\title{
Balance social de las cooperativas y las empresas sociales: el caso de la Cooperativa de Consumo El Grullo en Jalisco
}

Eduardo Enrique Aguilar Hernández

Magíster en Desarrollo Económico y

Cooperación Internacional. Miembro de la Red de Economía Solidaria de Guadalajara, Guadalajara, México. Correo electrónico: eduardoaguilar.h@hotmail.com

Recibido: 19 de agosto del 2016

Aprobado: 7 de noviembre del 2016

Cómo citar este artículo: Aguilar-Hernández, E. E. (2017). Balance social de las cooperativas y las empresas sociales: el caso de la cooperativa de consumo El Grullo en Jalisco. Cooperativismo \& Desarrollo, 110(25), 16-26. doi: https://doi.org/10.16925/ co.v25i110.1761.

\section{Resumen}

Propósito: el presente trabajo está enmarcado dentro del proyecto conjunto de cuatro universidades mexicanas que pretenden crear un sistema de evaluación del área social de las cooperativas y empresas sociales. Descripción: la evaluación se realiza mediante la aplicación de diversos instrumentos conjuntados dentro del "Manual de Procedimientos Administrativos" que evalúa los principios cooperativos establecidos por la Alianza Cooperativa Internacional. Punto de vista: este texto tiene el propósito de presentar los resultados de la aplicación de los instrumentos del "Manual de Procedimientos Administrativos" a la Cooperativa de Consumo El Grullo, localizada en el sur de Jalisco, México. Conclusiones: el análisis ofrece una visión de las fortalezas y debilidades de la actuación social de la cooperativa con el objetivo de generar lecciones para los demás entes de la economía solidaria. La utilización de los instrumentos presentados en el "Manual de Procedimientos Administrativos" son herramientas útiles que permiten la generación de indicadores para su posterior análisis. Los resultados de la aplicación del "Manual de Procedimientos Administrativos" ofrece una pauta a seguir, sin embargo, cabe aclarar que estos principios deben ser articulados con la misión establecida de la cooperativa.

Palabras clave: balance social, cooperativismo, economía solidaria, El Grullo, Jalisco, Manual de Procedimientos Administrativos. 


\title{
Social Balance of Cooperatives and Social Enterprises: Cooperativa de Consumo El Grullo in Jalisco Case
}

\begin{abstract}
Purpose: The present work is framed within the joint project of four Mexican universities that aim to create an evaluation system for the social area of cooperatives and social enterprises. Description: The evaluation is carried out applying several instruments found in the Manual of Administrative Procedures that evaluate the cooperative principles established by the International Cooperative Alliance. Point of view: This paper presents the results of the application of the Manual of Administrative Procedures' instruments to the Cooperativa de Consumo El Grullo, located in the south of Jalisco, Mexico. Conclusions: The analysis offers insight about the strengths and weaknesses of the social action of the cooperative with the objective of generating lessons for the other entities of the solidarity economy. The instruments presented in the Manual of Administrative Procedures constitute useful tools that allow the generation of indicators for later analysis. The results of the Manual of Administrative Procedures' application offer a guideline to follow, however, it should be clarified that these principles must be articulated with the cooperative's established mission.
\end{abstract}

Keywords: social balance, cooperativism, solidarity economy, El Grullo, Jalisco, Manual of Administrative Procedures.

\section{Balanço social das cooperativas e das empresas sociais: o caso da Cooperativa de Consumo El Grullo, em Jalisco}

\section{Resumo}

Propósito: este trabalho se encontra no âmbito do projeto conjunto de quatro universidades mexicanas que pretendem criar um sistema de avaliação da área social das cooperativas e das empresas sociais. Descrição: a avaliação é realizada mediante a aplicação de diversos instrumentos reunidos no Manual de Procedimentos Administrativos que avaliam os princípios cooperativos estabelecidos pela Parceria Cooperativa Internacional. Ponto de vista: este texto tem o propósito de apresentar os resultados da aplicação dos instrumentos do Manual de Procedimentos Administrativos à Cooperativa de Consumo El Grullo, localizada no sul de Jalisco (México). Conclusões: a análise oferece uma visão das fortalezas e das debilidades da atuação social da cooperativa com o objetivo de gerar lições para os demais entes da economia solidária. A utilização dos instrumentos apresentados no manual são ferramentas úteis que permitem a geração de indicadores para sua posterior análise. Os resultados da aplicação desse manual oferecem umas instruções a seguir; contudo, cabe esclarecer que esses princípios devem de ser articulados com a missão estabelecida da cooperativa.

Palavras-chave: balanço social, cooperativismo, economia solidária, El Grullo, Jalisco, Manual de Procedimentos Administrativos. 


\section{Introducción}

El día de hoy el cooperativismo y en general la economía solidaria en América Latina tiene un papel relevante, pues es un sistema económico disruptivo del sistema económico capitalista. No obstante, existe el peligro constante de que las iniciativas alternativas sean cooptadas por el sistema hegemónico; por tanto, es imprescindible la confección de herramientas que permitan evaluar la acción social de dichos emprendimientos. En ese sentido, Marañón y López (2013) indican que la evaluación debe ser multidimensional, haciendo referencia a las relaciones hombre-naturaleza, relaciones sociales de producción, viabilidad económica y legitimidad de las organizaciones económicas populares. Todo lo anterior se adopta en una perspectiva de tensión de reciprocidad y mercado: “Todos estos aspectos deberían evaluarse dentro de la tensión entre reciprocidad y mercado" (Marañón y López, 2013, p. 40) No obstante, esta propuesta todavía tiene que desarrollarse en instrumentos que puedan ser aplicados por las iniciativas económicas.

En esa misma línea, el cooperativismo a través de sus años ha desarrollado una serie de principios que los emprendimientos económicos de ese tipo tienen que cumplir. Estos principios están muy ligados a las consideraciones de Marañón y López (2013). Los principios cooperativos existen desde inicios del cooperativismo en el siglo XIX pero es hasta 1995 cuando la Alianza Cooperativista Internacional (ACI) hace una declaración de identidad cooperativa, en la cual se estandarizan siete principios cooperativos ${ }^{1}$.

La Escuela Nacional de Trabajo Social de la Universidad Nacional Autónoma de México ha realizado una titánica tarea de transformar los principios en instrumentos que puedan demostrar el trabajo de las cooperativas; los instrumentos se han conformado en un manual que tiene el "propósito de ser una herramienta que establezca los mecanismos necesarios para el registro de información de índole social por parte de las cooperativas y logre dar cuenta del trabajo realizado por estas" (Pérez et al., 2014, p. 1).

El trabajo se estructura conforme con la propuesta de seguimiento y evaluación de proyectos (Rodríguez y Zeballos, 2007), que comienza con una revisión sucinta del cooperativismo y el balance social cooperativo como base teórica; posteriormente, se centra en el análisis de los casos particulares utilizando la metodología del Manual de Procedimientos Administrativos para el Balance Social (MAPA) y de las entrevistas, y finaliza con las conclusiones, lecciones y recomendaciones hacia la cooperativa jalisciense. Cabe destacar que este no pretende ser un documento indulgente con la cooperativa, sino una herramienta que pretenda generar cambios para la construcción de alternativas emancipadoras dentro de la región visualizando fortalezas - para ampliarlas y reproducirlas - y debilidades - para que se convoque a un espacio de autocrítica y reflexión-. Es importante resaltar que este trabajo pretende ser no solo un punto de referencia de la situación actual de la cooperativa, sino uno que pueda servir como propiciador de cambios dentro de las estructuras. Se tiene en cuenta que los cambios drásticos muchas veces no generan los objetivos deseados, antes bien esto se logra generando transformaciones paulatinas con tiempos y formas de cada realidad organizacional. Las cooperativas en su caso tendrían que acoplar lo que este estudio indique en relación con la misión propuesta de su organización.

Para comenzar el análisis se precisa revisar conceptos básicos para el posterior desarrollo del documento: en primer lugar, examinar el cooperativismo sería una tarea larga, y este no pretende ser un trabajo histórico, por lo que solamente se resalta el hecho de que en México esta corriente ha sido ambivalente a través del tiempo. Por una parte, dentro del marco legal-legislativo, ha dado espacio para confusiones por desprendimiento dentro del Código de Comercio (Izquierdo, 2012) y por sus fluctuaciones dentro del apoyo gubernamental por su acercamiento o alejamiento de las ideas socialistas/neoliberales en el siglo $\mathrm{xx}$. Actualmente, la ley menciona tres tipos de cooperativas que conforman el sistema cooperativo: de consumidores de bienes o servicios; de productores de bienes o servicios, y de ahorro y préstamo ${ }^{2}$. Dicho sistema cooperativo puede conformar una alternativa económica que adopte un enfoque social, pues se crearía un círculo virtuoso en el que las cooperativas de consumo obtendrían sus productos y servicios de las cooperativas de producción, las cuales, a su vez, serían financiadas por las cooperativas de ahorro
Alianza Cooperativista Internacional (revisado el 13 abril del 2015): http://www.aciamericas.coop/Principios-y-Valores-Cooperativos-4456
2 Dentro del presente trabajo, la referencia a la ley es para hablar específicamente sobre la Ley General de Sociedades Cooperativas (2009). 
y préstamo; y todas ellas podrían confluir en uniones de cooperativas, y estas uniones podrían organizarse dentro de federaciones y confederaciones de cooperativas. Dicha organización tendría como base funcional una colaboración diferente a aquella de las empresas capitalistas ${ }^{3}$ : es una con base ética pensada por el bien común, y basada en principios y valores cooperativos.

En México, se han creado muchas sociedades cooperativas que se han comportado como empresas capitalistas y dejan de lado sus objetivos tanto sociales como ambientales, se han constituido para obtener ventajas fiscales (Izquierdo, 2012) o para bajar recursos en el ámbito federal o internacional sin realmente cumplir con lo establecido en la visión de una cooperativa, la de ser una herramienta al servicio de la comunidad.

\section{Cooperativismo: ¿empresas con responsabilidad social o una opción de transformación?}

Sin embargo, hoy en día existen corrientes que toman el cooperativismo no solo como empresas con responsabilidad social, sino realmente como una verdadera herramienta que puede llegar a propiciar la transformación social. Este trabajo parte desde ese principio, pensando en que el sistema económico actual produce desigualdad de recursos y poder; formas de sociabilidad empobrecidas, al promover el provecho personal antes que la solidaridad; ver a las personas como fuentes posibles de enriquecimiento, y explotar irracionalmente los recursos naturales; en cambio, las empresas cooperativas se fundan bajo valores totalmente opuestos, es decir, autonomía, democracia, equidad, cooperación y solidaridad (De Sousa y Ramírez, 2006).

Actualmente vivimos en una crisis civilizatoria que se conforma de diversas crisis como la social, económica, política, ambiental, cultural (Günter, 2014); pero por el lado positivo, dentro de las crisis surgen herramientas/iniciativas que ayuden a superarla, así las empresas cooperativas se han formulado como esenciales para la superación de dicha crisis y la construcción de un mundo más justo y próspero para todas y todos.

3 Laura Collin (2012) indica que, dentro del sistema capitalista, también existe cooperación, pero esta no pretende ser para el bien común, sino maximizar el beneficio propio de los agentes económicos.

\section{Análisis de casos especiales con metodología del MAPA}

Dentro de la actual evaluación a cooperativas se utilizó el MAPA. La metodología consiste en hacer una revisión del cumplimiento de los siete principios cooperativistas; se utilizan instrumentos tanto cuantitativos como cualitativos enfocados a ofrecer resultados que sean fácilmente identificables y que puedan ser utilizados por los socios cooperativistas, pues el MAPA ha sido diseñado como una herramienta de autoevaluación.

Se considera apropiado que la implementación del MAPA sea llevada a cabo por los mismos socios, debido a la importancia de democratizar la participación dentro de las cooperativas. De igual manera, es primordial que los socios sean partícipes del proceso para posibilitar el acceso a la información que se desarrolla dentro de la organización y fortalecer los lazos de identidad cooperativa, responsabilizándose y sensibilizándose de su trabajo. (Pérez et al., 2014, p. 2)

Según MAPA, este indica que cada principio cooperativista es evaluado por diferentes dimensiones descritas en la tabla 1.

\section{Mi Cooperativa de Consumo en El Grullo, Jalisco}

La Sociedad Cooperativa Rural de Compra y Venta en Común y Comercialización El Grullo (SCL) es un caso emblemático del cooperativismo nacional; es considerada generalmente como un caso de éxito tanto por su historia como por su trayectoria ${ }^{4}$, lo cual la sitúa como un referente regional. Se encuentra ubicada al suroeste de Jalisco dentro del Grullo, perteneciente a la sierra de Amula, por lo que dicha región está enmarcada en un sistema montañoso que aleja a este municipio y los aledaños de una comunicación fluida con la capital del estado. Por este mismo hecho, la región ha ido forjando una identidad propia en relación con su medio natural, su clima y su historia; especialmente, este municipio tiene una tradición en el cooperativismo, el cual tiene que entenderse primeramente para poder acercarse a la historia de la cooperativa.

Izquierdo (2012) señala que "es sin duda un caso de éxito, fue fundada en 1974 y es la más grande Cooperativa de Consumo en México, cuenta con un registro de más de 4,300 socios, donde cada socio representa una familia; esto equivale al $75 \%$ de la población de El Grullo, Jalisco". 
Tabla 1

Principios cooperativos y dimensiones evaluadas

\begin{tabular}{|c|c|c|c|}
\hline Principio & Dimensión & Descripción del principio & \\
\hline 1 & $\begin{array}{l}\text { Membresía } \\
\text { abierta y } \\
\text { voluntaria }\end{array}$ & $\begin{array}{l}\text { - Apertura voluntaria } \\
\text { - Salida voluntaria } \\
\text { - No discriminación } \\
\text { Representa la apertura de la cooperativa con relación al campo } \\
\text { laboral y las relaciones en las responsabilidades entre los socios. }\end{array}$ & $\begin{array}{l}\text { Las cooperativas son organizaciones } \\
\text { voluntarias abiertas para todas aque- } \\
\text { llas personas dispuestas a utilizar } \\
\text { sus servicios y dispuestas a aceptar } \\
\text { las responsabilidades que conlleva } \\
\text { la membrecía, sin discriminación de } \\
\text { género, raza, clase social, posición } \\
\text { política o religiosa. }\end{array}$ \\
\hline 2 & $\begin{array}{l}\text { Control } \\
\text { democrá- } \\
\text { tico de los } \\
\text { miembros }\end{array}$ & $\begin{array}{l}\text { - Participación en asambleas } \\
\text { - Accesibilidad a cargos sociales } \\
\text { - } \text { Equilibrio real de poder entre los asociados } \\
\text { Identificar si hay participación o no de los socios durante las } \\
\text { asambleas. }\end{array}$ & $\begin{array}{l}\text { Las cooperativas son organizacio- } \\
\text { nes democráticas controladas por } \\
\text { sus integrantes, quienes participan } \\
\text { activamente en la definición de las } \\
\text { políticas y en la toma de decisiones. } \\
\text { Los hombres y mujeres elegidos para } \\
\text { representar a su cooperativa respon- } \\
\text { den ante los miembros. }\end{array}$ \\
\hline 3 & $\begin{array}{l}\text { Participa- } \\
\text { ción econó- } \\
\text { mica de los } \\
\text { socios }\end{array}$ & $\begin{array}{l}\text { - Valor agregado cooperativo visibilizado } \\
\text { - Valor agregado cooperativo invisibilizado } \\
\text { Contempla de manera general las ganancias o rendimientos a distri- } \\
\text { buir entre los socios de la cooperativa, así como de los trabajadores. }\end{array}$ & $\begin{array}{l}\text { Los miembros contribuyen de } \\
\text { manera equitativa y controlan de } \\
\text { manera democrática el capital de la } \\
\text { cooperativa. Por lo menos una parte } \\
\text { de ese capital es propiedad común de } \\
\text { la cooperativa. }\end{array}$ \\
\hline 4 & $\begin{array}{l}\text { Autonomía } \\
\text { e indepen- } \\
\text { dencia }\end{array}$ & $\begin{array}{l}\text { - Independencia financiera } \\
\text { Participación de los socios cooperativistas en otras organiza- } \\
\text { ciones } \\
\text { Movilidad de los miembros de los consejos de administración } \\
\text { y vigilancia } \\
\text { Recursos propios de la cooperativa que le permiten llevar a cabo sus } \\
\text { actividades sin depender excesivamente de recursos provenientes de } \\
\text { organizaciones externas (donativos, préstamos, financiamiento). }\end{array}$ & $\begin{array}{l}\text { Si las cooperativas se ponen de } \\
\text { acuerdo con otras organizaciones } \\
\text { (incluyendo gobiernos) o tienen } \\
\text { capital de fuentes externas, lo } \\
\text { realizan en términos que aseguren el } \\
\text { control democrático por parte de sus } \\
\text { miembros y mantengan la autonomía } \\
\text { de la cooperativa. }\end{array}$ \\
\hline 5 & $\begin{array}{l}\text { Educación, } \\
\text { entrena- } \\
\text { miento e } \\
\text { informa- } \\
\text { ción }\end{array}$ & $\begin{array}{l}\text { - Plan de trabajo de actividades de capacitación y educación } \\
\text { - Inversión en educación y capacitación } \\
\text { - Perfil de los socios capacitados y tipología de la capacitación } \\
\text { que reciben } \\
\text { - Autopercepción y percepción de la comisión de educación } \\
\text { Elaboración de un plan de trabajo que permita el registro y valora- } \\
\text { ción de las actividades de educación y capacitación. }\end{array}$ & $\begin{array}{l}\text { Se registrará la información relativa } \\
\text { a las actividades de la comisión de } \\
\text { educación, o, en dado caso, de todos } \\
\text { aquellos eventos, cursos, conferen- } \\
\text { cias, talleres, carteles y demás, desti- } \\
\text { nados a educar, capacitar e informar } \\
\text { a los socios de la cooperativa. }\end{array}$ \\
\hline 6 & $\begin{array}{l}\text { Coopera- } \\
\text { ción entre } \\
\text { coopera- } \\
\text { tivas }\end{array}$ & $\begin{array}{l}\text { - Integración a efectos representativos } \\
\text { - Integración a efectos de negocios } \\
\text { - Colaboraciones brindadas y recibidas con otras cooperativas } \\
\text { Afiliación y asistencia a eventos de organismos sectoriales e intrase- } \\
\text { ctoriales, y la participación que han tenido en ellos. }\end{array}$ & $\begin{array}{l}\text { Las cooperativas sirven más eficien- } \\
\text { temente a sus asociados y fortalecen } \\
\text { al movimiento cooperativo traba- } \\
\text { jando mancomunadamente a través } \\
\text { de estructuras locales, nacionales, } \\
\text { regionales e internacionales. }\end{array}$ \\
\hline 7 & $\begin{array}{l}\text { Compro- } \\
\text { miso de la } \\
\text { cooperativa } \\
\text { con su } \\
\text { comunidad }\end{array}$ & $\begin{array}{l}\text { - La cooperativa y su comunidad o estrategias-proceso para la } \\
\text { vinculación de la cooperativa con su comunidad } \\
\text { - Problemas comunitarios } \\
\text { - Destino y uso de las donaciones realizadas por la cooperativa a } \\
\text { su comunidad } \\
\text { - Mecanismos de seguimiento, monitoreo y evaluación de las } \\
\text { acciones de vinculación con la comunidad } \\
\text { - Manejo sustentable de la cooperativa } \\
\text { Busca hacer visible las diversas formas en las que las cooperativas se } \\
\text { vinculan y viven en la comunidad donde están insertadas. }\end{array}$ & $\begin{array}{l}\text { A la vez que atienden las necesidades } \\
\text { de sus asociados, las cooperativas } \\
\text { trabajan en pro del desarrollo susten- } \\
\text { table de sus comunidades mediante } \\
\text { políticas aprobadas por aquellos. }\end{array}$ \\
\hline
\end{tabular}

Fuente: elaboración propia con información del "Manual de Procedimientos Administrativos para el Balance Social”. 
La población del Grullo tiene un manejo muy particular del cooperativismo, que tendría que abordarse en estudios posteriores, pero que se hace menester tener en cuenta. La cantidad de cooperativas que existen de diversas actividades hacen que sea parte común del lenguaje del grullense. Este hecho es fundamental para la cooperativa de consumo, ya que la construcción de esa cultura también explica en parte la larga vida de dicha organización; las instituciones no pueden despegarse de la cultura local $\mathrm{y}$ de las prácticas comunitarias en las que se inserta.
Para la fecha en que se realizó el trabajo de campo ${ }^{5}$ la organización tiene 41 años de trabajo, cuenta con tres tiendas, con 131 socios que desempeñan funciones dentro de la cooperativa y más de $3800^{6}$ socios activos que representan a familias del municipio, y está en la fase de reestructuración posterior a una crisis financiera que casi hizo que cerrara las puertas. En esta etapa de la cooperativa, se está haciendo un trabajo de revisión de su funcionamiento interno, por lo que la aplicación del MAPA resulta de especial atención; los resultados de la aplicación se explicitan en la tabla 2.

Tabla 2

Resultados de los instrumentos del MAPA

\begin{tabular}{|c|c|}
\hline Principio & Dimensión \\
\hline \multirow{3}{*}{$\begin{array}{l}\text { Membresía abierta } \\
\text { y voluntaria }\end{array}$} & $\begin{array}{l}\text { - Apertura voluntaria: } \\
\text { Son aproximadamente } 3.800 \text { socios que representan una familia. Existen socios extranjeros y no se toma en } \\
\text { cuenta la religión que profesan para su admisión. Hay dos tipos de socios: los socios consumidores que tienen } \\
\text { acceso a comprar en la tienda y participar en las asambleas, y los socios comisionados que son aquellos que } \\
\text { realizan labores tanto operativas como administrativas dentro de las tiendas; estos últimos tienen que pasar } \\
\text { por un proceso de evaluación de aptitudes para desempeñar el cargo que se ha solicitado; según sus registros } \\
\text { se tiene una mayoría de mujeres socias, el consejo de administración habla de un 52\% de mujeres del total de } \\
\text { socios; además la cooperativa cuenta con socios con } 40 \text { años de antigüedad, es decir, socios fundadores de la } \\
\text { organización. } \\
\text { Actualmente, los socios comisionados laboran } 48 \text { horas semanales. }\end{array}$ \\
\hline & $\begin{array}{l}\text { - Salida voluntaria: } \\
\text { La salida de los socios no es común: es una tasa muy baja la salida de socios consumidores. Prácticamente, en } \\
\text { los últimos cinco años, no ha habido salidas conflictivas por parte de los socios colaboradores; las bajas que se } \\
\text { han dado son por deceso de las personas. }\end{array}$ \\
\hline & $\begin{array}{l}\text { - No discriminación: } \\
\text { Existen tres hombres con capacidades diferentes como socios colaboradores; y los cargos en comisiones y en los } \\
\text { puestos administrativos están distribuidos equitativamente entre hombres y mujeres, no existen porcentajes del } \\
\text { número de socios con capacidades diferentes. }\end{array}$ \\
\hline Balance & $\begin{array}{l}\text { La cooperativa cumple con este principio cooperativo atendiendo a las dimensiones evaluadas; no obstante, } \\
\text { siempre se puede fortalecer este proceso; sistematizar la información del crecimiento o disminución del } \\
\text { número de socios, su escolaridad, grupo de edad u horas de trabajo puede darles herramientas y visión para } \\
\text { la toma de decisiones; de igual manera, hacer énfasis en la equidad de género que aunque existe un equilibrio } \\
\text { entre hombres y mujeres en las cuestiones administrativas el trabajo sería impulsar una política para que eso se } \\
\text { siga replicando en el tiempo. }\end{array}$ \\
\hline $\begin{array}{l}\text { Control demo- } \\
\text { crático de los } \\
\text { miembros }\end{array}$ & $\begin{array}{l}\text { - Participación en asambleas: } \\
\text { Las asambleas funcionan conforme a la ley, se asignan diversos recursos para la convocatoria a las asambleas, } \\
\text { tanto dentro de las tiendas como fuera de ellas, desde correos electrónicos o publicaciones en periódicos } \\
\text { locales. } \\
\text { De los aproximadamente } 3800 \text { socios compradores, a la última asamblea asistieron aproximadamente } 135 \\
\text { socios, es decir, el } 3 \% \text { de los socios compradores. } \\
\text { Una constante es que la participación se ha inclinado a cierta población de edad adulta, ya que no se ve la parti- } \\
\text { cipación de jóvenes y también ha quedado registrado que la mayoría de participantes son mujeres. } \\
\text { A las asambleas generales no acuden los socios comisionados. }\end{array}$ \\
\hline
\end{tabular}




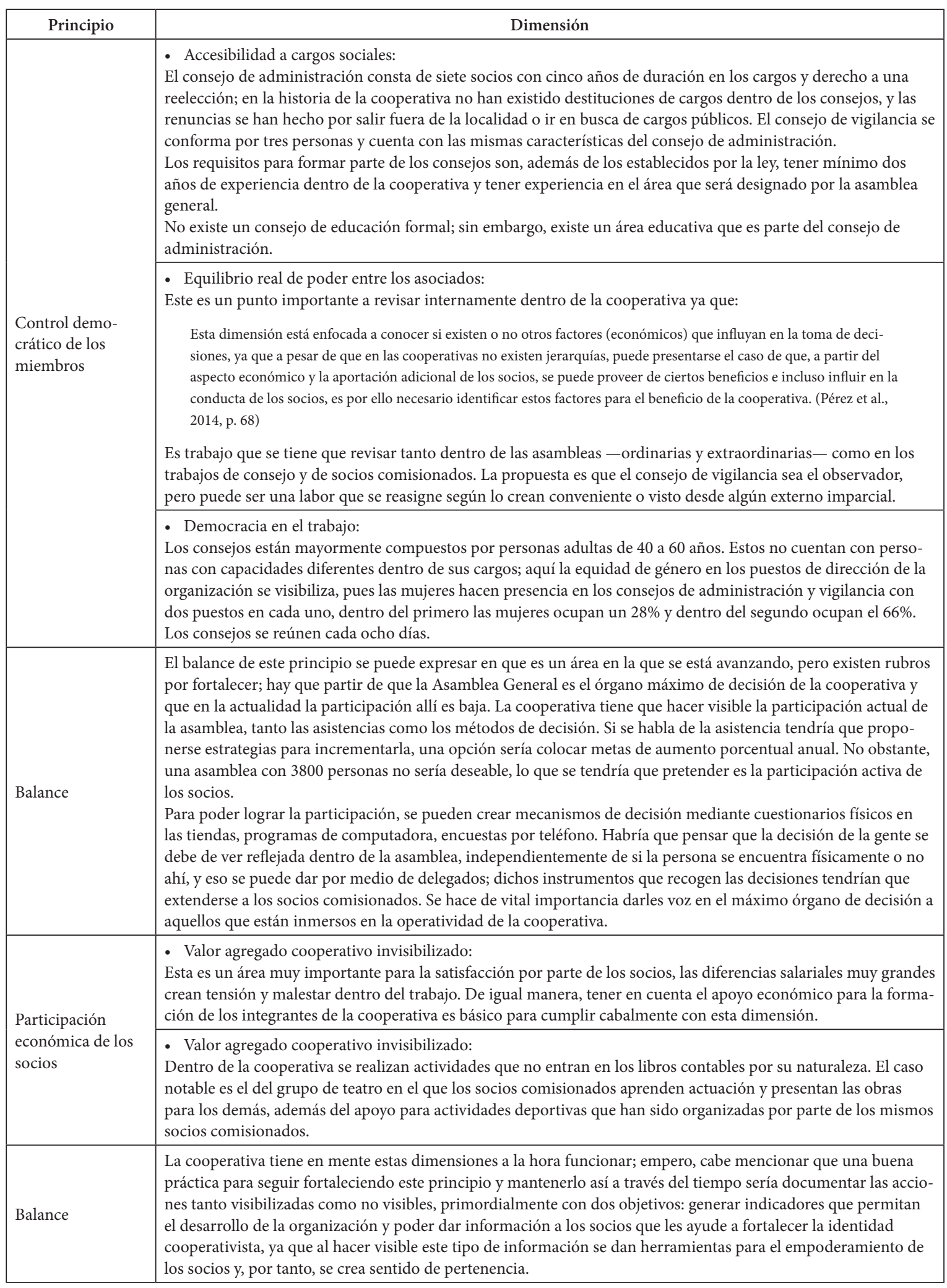




\begin{tabular}{|c|c|}
\hline Principio & Dimensión \\
\hline \multirow[t]{3}{*}{$\begin{array}{l}\text { Autonomía e } \\
\text { independencia }\end{array}$} & $\begin{array}{l}\text { - Independencia financiera: } \\
\text { La cooperativa está en un proceso de reestructuración financiera, casi ha superado la deuda que la estaba asfixiando } \\
\text { a tal punto que se preveía cerrarla, se siguen teniendo compromisos con bancas comerciales privadas, pero se } \\
\text { visualiza la superación de esta etapa para una posterior independencia financiera en un corto-mediano plazo. } \\
\text { La cooperativa ha recibido donaciones por parte del Gobierno federal. } \\
\text { Las ventas de la cooperativa son para sus dos tipos de socios, y las ventas están abiertas al público en general. } \\
\text { Dentro de esta, se está compitiendo con empresas trasnacionales como Walmart y franquicias como Oxxo. }\end{array}$ \\
\hline & $\begin{array}{l}\text { - Participación de los socios cooperativistas en otras organizaciones: } \\
\text { La participación de los socios en organizaciones fuera de la cooperativa no afecta el funcionamiento de la orga- } \\
\text { nización. }\end{array}$ \\
\hline & $\begin{array}{l}\text { - Movilidad de los miembros de los consejos de administración y vigilancia. } \\
\text { Existe la movilidad de los miembros de los consejos en un proceso asincrónico, es decir, no todos los puestos del } \\
\text { consejo se eligen en el mismo momento, los consejos de administración y vigilancia actuales están conformados } \\
\text { por personas que son recién elegidos, aquellos que llevan uno, dos y cuatro años; el tiempo de pertenencia en los } \\
\text { consejos se aumentó de tres a cinco años. } \\
\text { Los socios propuestos a los consejos son aquellos que cumplan con lo establecido por la ley y además de los } \\
\text { requisitos del puesto del consejo, dichos socios son elegidos en la asamblea general. }\end{array}$ \\
\hline Balance & $\begin{array}{l}\text { Dentro de este principio, la cooperativa demuestra un avance, pues su manejo financiero ha sido de tal manera exi- } \\
\text { toso que pudo superar una situación de quiebra, su deuda se redujo y pudo seguir en operación teniendo margen } \\
\text { de actuación frente a los acreedores. Ahora bien, es importante tener en cuenta que este pasivo puede truncar el } \\
\text { desarrollo de la función social de la cooperativa, ya que el origen de dichos compromisos es hacia la banca privada, } \\
\text { la cual no funciona bajo la lógica de la solidaridad, por lo que el manejo inadecuado de la deuda puede que se } \\
\text { vuelva a convertir en algo que ponga en peligro a la organización; también se tiene que pensar en el fortalecimiento } \\
\text { de los fondos que establece la ley para poder tener mayor manejo de recursos para eventualidades e independencia. } \\
\text { Para cumplir cabalmente con este principio, la cooperativa tendría que buscar formas de financiamiento } \\
\text { alternativas a las de la banca comercial, apelar tanto a las cooperativas de ahorro y crédito del mismo munici- } \\
\text { pio y de la región para que sean sus fuentes de apalancamiento, además con la experiencias obtenidas de los } \\
\text { tiempos de abundancia y de escasez de recursos se tendría que visualizar un acercamiento a los organismos } \\
\text { nacionales de cooperativas financieras proponerles estrategias que realmente sean funcionales para el desa- } \\
\text { rrollo del movimiento cooperativo. } \\
\text { No obstante la independencia financiera, la autonomía de la cooperativa es funcional y positiva, aunque la } \\
\text { recomendación de la sistematización de la información nunca está de más, pues ofrece la posibilidad de generar } \\
\text { indicadores que van desde tener un panorama de la posición actual de la organización hasta enfocar la acción y } \\
\text { tomar decisiones informadas. }\end{array}$ \\
\hline \multirow{4}{*}{$\begin{array}{l}\text { Educación, } \\
\text { entrenamiento e } \\
\text { información }\end{array}$} & $\begin{array}{l}\text { - Plan de trabajo de actividades de capacitación y educación: } \\
\text { El área de educación cuenta con un plan anual de trabajo el cual contiene actividades como lograr más asistencia } \\
\text { dentro de la asamblea, informar de los beneficios del cooperativismo, fomentar la historia de la cooperativa } \\
\text { entre los socios, cursos de superación personal y consultas de nutrición, inclusive se han planeado programas de } \\
\text { capacitación para la separación de residuos. }\end{array}$ \\
\hline & $\begin{array}{l}\text { - Inversión en educación y capacitación: } \\
\text { Se hace la inversión en educación y capacitación para ir cumpliendo con el plan anual; no se tiene un concen- } \\
\text { trado de los registros de las inversiones en estas áreas. } \\
\text { A los socios recién comisionados en labores se les da una charla introductoria al funcionamiento del cooperati- } \\
\text { vismo y de la historia de la cooperativa. }\end{array}$ \\
\hline & $\begin{array}{l}\text { - Perfil de los socios capacitados y tipología de la capacitación que reciben: } \\
\text { Según se requiera para desempeñar las labores es como se asignan las capacitaciones para los socios. No se } \\
\text { cuenta con una tipología de capacitación específica. }\end{array}$ \\
\hline & $\begin{array}{l}\text { - Autopercepción y percepción de la comisión de educación: } \\
\text { No se llevaron a cabo las encuestas de percepción de la comisión de educación por falta de tiempo dentro de la } \\
\text { visita de campo. Es menester que la cooperativa realice este diagnóstico previo para poder referenciar la activi- } \\
\text { dad de educación cooperativa y que sirva de guía para fortalecer el proceso. }\end{array}$ \\
\hline
\end{tabular}




\begin{tabular}{|c|c|}
\hline Principio & Dimensión \\
\hline Balance & $\begin{array}{l}\text { Esta es una de las áreas más importantes dentro de las cooperativas, pues la educación puede transformar rea- } \\
\text { lidades. Para las organizaciones, es importante porque genera identidad y fortalecimiento de los individuos. } \\
\text { Es de esa manera que se recomienda, en primer lugar, la creación del consejo de educación con el respectivo } \\
\text { énfasis en el fondo educativo, ya que ofrece autonomía a este consejo. Se tendría que pensar en estructurar el } \\
\text { plan anual de actividades en dos tipos de áreas: el primer referente a la educación y capacitación de los socios } \\
\text { comisionados, y otra de educación y capacitación a socios consumidores. Cada una tiene objetivos especí- } \\
\text { ficos, pero se centran en la creación de una conciencia cooperativista fundada en los valores y principios de } \\
\text { dicho movimiento. } \\
\text { Una de las diferencias radicales entre las empresas convencionales y las empresas sociales, o cooperativas, es } \\
\text { la identidad de los socios: mientras que en la primera se ven como trabajadores que tienen la relación con la } \\
\text { empresa de cumplir un horario y recibir un salario, en una cooperativa la persona se siente dueña de la organiza- } \\
\text { ción y por ende su compromiso es mayor. } \\
\text { En este caso, la educación tendría que fortalecer la identidad dentro de los socios comisionados atendiendo al } \\
\text { hecho de que ellos son parte de la cooperativa, y los socios consumidores fortaleciendo el hecho de que esa empresa } \\
\text { está hecha por ellos y para ellos, que ellos son parte, y, entonces, tienen derecho a hablar y decidir sobre su futuro. } \\
\text { Dentro de las dimensiones evaluadas en este principio, se precisan crear indicadores para visualizar los recursos } \\
\text { del área específicamente y la administración que se le va a dar, de igual manera el ámbito subjetivo de los socios } \\
\text { implementando las cuestiones de autopercepción que se proponen dentro del mapa. }\end{array}$ \\
\hline \multirow{3}{*}{$\begin{array}{l}\text { Cooperación entre } \\
\text { cooperativas }\end{array}$} & $\begin{array}{l}\text { - Integración a efectos representativos: } \\
\text { La cooperativa de consumo ha enviado representantes a diversos foros a los que ha sido invitada, por ejemplo, } \\
\text { aquellos promovidos por universidades regionales, estatales o el Instituto Nacional de Economía Social, princi- } \\
\text { palmente para compartir la experiencia y su historia como organización. }\end{array}$ \\
\hline & $\begin{array}{l}\text { - Integración a efectos de negocios: } \\
\text { La cooperativa integra productos de otras cooperativas en sus tiendas; no obstante, no existen alianzas que } \\
\text { fortalezcan las relaciones. Estas son del tipo comercial estándar, inclusive se llega a notar que existe una relación } \\
\text { de cercanía o cooperación con las grandes empresas transnacionales. } \\
\text { Existen cooperativas regionales que surten productos a las tiendas las cuales pueden ser aprovechadas para } \\
\text { fortalecer esta dimensión. }\end{array}$ \\
\hline & $\begin{array}{l}\text { - Colaboraciones brindadas y recibidas con otras cooperativas: } \\
\text { La cooperativa propició la creación de una nueva cooperativa agrícola, de ahí en adelante, no se registra la realiza- } \\
\text { ción o celebración de actividades recientemente; sin embargo, la organización tiene apertura para que diferentes } \\
\text { actores sociales puedan recibir apoyo para la conformación de nuevos entes cooperativos o diversas actividades. }\end{array}$ \\
\hline Balance & $\begin{array}{l}\text { El balance de ese principio se traduce en que es un área de oportunidad de la cual se puede trabajar y sacar } \\
\text { mucho provecho, desde buscar la incorporación a uniones de cooperativas de actividades diversas ya existen- } \\
\text { tes dentro del estado o del país, así como propiciar la creación de este tipo de entes. Estas son actividades que } \\
\text { se tendrían que tener en mente sobre todo pensando en la base de la solidaridad y el beneficio colectivo. Si } \\
\text { actualmente la organización se encuentra en un periodo de reestructuración financiera se tendría que pensar } \\
\text { en que las alianzas comerciales con cooperativas cumplen dos objetivos: por una parte, el fortalecimiento del } \\
\text { área financiera y, por otra, el trabajo del área social, es decir, se trabajan dos objetivos en vez de solamente } \\
\text { uno. } \\
\text { La disposición a apoyar la creación de cooperativas es muy positiva, aun así, esa disposición pudiese conver- } \\
\text { tirse en el principio de transformación económica de la región. Como la cooperativa ya es un ente económico } \\
\text { de relevancia, puede fungir como un semillero cooperativista. No es simplemente esperar a que la comunidad } \\
\text { se acerque, sino hacer una revisión de las necesidades de la cooperativa para poder generar iniciativas que las } \\
\text { puedan cubrir. Si, por ejemplo, hace falta servicio técnico para las computadoras, se puede generar una alianza } \\
\text { con la universidad para poder crear una cooperativa que ofrezca ese servicio. }\end{array}$ \\
\hline $\begin{array}{l}\text { Compromiso de la } \\
\text { cooperativa con su } \\
\text { comunidad }\end{array}$ & $\begin{array}{l}\text { - La cooperativa y su comunidad o estrategias-proceso para la vinculación de la cooperativa con su comunidad: } \\
\text { La cooperativa tiene } 41 \text { años dentro de la comunidad: no se tiene en los planes hacer un diagnóstico comunitario ni } \\
\text { tampoco una estrategia fija para la vinculación con el entorno más allá de los fines explícitos de la cooperativa. } \\
\text { No obstante, se tienen vínculos con agrupaciones que trabajan con personas que tienen capacidades diferentes: } \\
\text { adultos mayores, personas alcohólicas o farmacodependientes, y población infantil; no se cuenta con relación } \\
\text { con otros grupos en situación de vulnerabilidad. }\end{array}$ \\
\hline
\end{tabular}




\begin{tabular}{|c|c|}
\hline Principio & Dimensión \\
\hline \multirow{4}{*}{$\begin{array}{l}\text { Compromiso de la } \\
\text { cooperativa con su } \\
\text { comunidad }\end{array}$} & $\begin{array}{l}\text { Problemas comunitarios: } \\
\text { Los socios de la cooperativa conocen los problemas comunitarios porque son parte de ella, además a los socios } \\
\text { de los consejos de administración y vigilancia se les hace partícipes de los procesos comunitarios por invitacio- } \\
\text { nes tanto por las autoridades locales como por organizaciones de la sociedad civil. } \\
\text { La cooperativa ha realizado actividades ambientales y culturales abiertas para la comunidad, ha trabajado } \\
\text { campañas de sensibilización ambiental para disminuir la utilización de campañas de plástico, así como de } \\
\text { integración social como caminatas, festejos para celebrar el día de la madre, del padre o del niño además de la } \\
\text { promoción de actividades tradicionales de la región. }\end{array}$ \\
\hline & $\begin{array}{l}\text { Destino y uso de las donaciones realizadas por la cooperativa a su comunidad: } \\
\text { La cooperativa ha dado donaciones monetarias y en especie, tanto a diversas organizaciones de la sociedad civil } \\
\text { como individuales en diversas ocasiones, por ejemplo, cuando han ocurrido desastres naturales, como inunda- } \\
\text { ciones, la cooperativa ha donado a los habitantes afectados; empero, no se cuenta con un registro concentrado } \\
\text { de dichas actividades. }\end{array}$ \\
\hline & $\begin{array}{l}\text { - Mecanismos de seguimiento, monitoreo y evaluación de las acciones de vinculación con la comunidad: } \\
\text { no se cuentan con mecanismos de seguimiento, monitoreo y evaluación de los programas y acciones dirigidos } \\
\text { hacia la comunidad. }\end{array}$ \\
\hline & $\begin{array}{l}\text { - Manejo sustentable de la cooperativa: } \\
\text { La comunidad en la que se suscribe la cooperativa es rural y cuenta con un avance en el uso eficiente de recur- } \\
\text { sos, su principal enfoque ha sido la disminución de residuos, la basura se separa y se le destina para su reciclaje } \\
\text { o reutilización. Además, otro de los ejes es la reducción de energía eléctrica; se ha recibido capacitación por } \\
\text { parte de diversas organizaciones para cumplir dicho objetivo, y se han emprendido acciones como cambiar las } \\
\text { instalaciones eléctricas por aquellas eficientes en el uso de la energía como iluminación LED. } \\
\text { La cooperativa cumple con diversas acciones para sensibilizar a la comunidad como el consumo directo de los } \\
\text { productores locales, realización de la Expocooperativa y diversos foros temáticos. }\end{array}$ \\
\hline Balance & $\begin{array}{l}\text { La cooperativa tiene un fuerte compromiso con la comunidad y ha desarrollado actividades para trabajar y } \\
\text { ha sabido cumplir con su papel dentro de su entorno. La observación dentro de este principio sería establecer } \\
\text { planes de trabajo a corto, mediano y largo plazo a los cuales se les pueda dar seguimiento, monitoreo y evalua- } \\
\text { ción de las acciones realizadas en la comunidad. Se recomienda que estos planes de trabajo sean construidos } \\
\text { mediante un proceso de metodología participativa, es decir, que lo construyan en conjunto los socios de la } \\
\text { cooperativa y las personas fuera de la organización para lograr un impacto mayor. } \\
\text { En relación con el principio anterior, se hace preciso mencionar una buena práctica, la cual es fortalecer la coopera- } \\
\text { ción con las empresas locales, familiares o sociales, desde el hecho de demarcar un área específica de estos productos } \\
\text { dentro de las tiendas para que tengan mayor visibilidad hasta promover un acercamiento de los productores con los } \\
\text { socios consumidores y los socios comisionados para sensibilizarlos sobre el por qué deberían de ser consumidos sus } \\
\text { productos en vez de aquellos de empresas trasnacionales. Todas estas acciones deberán de ser registradas para visuali- } \\
\text { zar los avances que se vayan obteniendo. }\end{array}$ \\
\hline
\end{tabular}

\section{Conclusiones}

Es importante este tipo de evaluaciones para todo tipo de cooperativas ya que sus objetivos principales están enmarcados en el área social, dentro del caso específico de la Cooperativa de Consumo en El Grullo cuenta con grupo personas con visión y amor por la iniciativa; no obstante, se precisa reforzar la identidad cooperativista. En estos tiempos de reestructuración, existe el peligro de que la cooperativa, ante las necesidad de obtener recursos para librarse de la deuda existente con la banca comercial o las constantes amenazas externas como las tiendas de conveniencia y los supermercados de la zona, pueda perder su sentido social e ingrese en la lógica de competencia de mercado con las empresas trasnacionales, lo cual sería un error; al contrario, ante este escenario se precisa reafirmar y fortalecer la identidad cooperativa no tan solo como empresa con responsabilidad social, sino como una opción viable de cambio de la realidad regional. La madurez de la organización permite ser un punto de cambio dentro de la comunidad, por ejemplo, aumentar los empleos y la calidad de estos; recuperar prácticas económicas locales y regionales, y fortalecer la cultura local y cuidar el medio ambiente podrían ser horizontes que los socios de la cooperativa pueden cumplir.

La evaluación por parte del MAPA ofrece una pauta a seguir. Cabe aclarar que estos principios deben de ser articulados por la misión de la cooperativa y trabajados en planes con metas concretas en cambios paulatinos. La utilización de los instrumentos presentados en el mapa son buenas herramientas que permiten la 
generación de indicadores para su posterior análisis. En este momento, la cooperativa cuenta con mucho trabajo hecho que se necesita visibilizar, no de una manera presuntuosa como se pudiese pensar, sino para que la cooperativa tenga referentes del camino a seguir y para que pueda servir como ejemplo a otras cooperativas. Recordemos que el conocimiento es acumulativo y que la sociedad precisa de conocer tanto las buenas prácticas como los errores para poder reproducir experiencias que promuevan una vida buena.

\section{Lecciones}

La Cooperativa El Grullo deja lecciones muy importantes, no solo para las cooperativas regionales o estatales, sino también nacionales y hasta para el movimiento en otros países. Las experiencias por las que ha pasado, tanto buenas como malas, a lo largo de 40 años permite que otras de más reciente creación se fortalezcan. Es por eso que tienen que ser documentadas y presentadas para que las conozcan tanto ámbitos sociales, como gubernamentales y académicos.

\section{Referencias}

Collin, L. (2012). Economía solidaria: ¿capitalismo moralizado o movimiento contracultural? Tlaxcala: Coltlax.
De Sousa, B. y Ramírez, C. (2006). Para ampliar el canon de la producción. En B. De Sousa Santos (Ed.), Desarrollo, eurocentrismo y economía popular. Más allá del paradigma neoliberal (pp. 130-201). Caracas: Gobierno de Venezuela.

Günter, M. (2014). Crisis civilizatoria y racionalidades. En J. Contreras y M. Günter (Eds.), Laberintos de la racionalidad ¿crisis civilizatoria? (pp. 15-40). México D. F.: Itaca/UNAM.

Izquierdo, M. (2012). Comentarios en torno a las sociedades cooperativas en México. Boletín de la Asociación Internacional de Derecho Cooperativo, (46), 53-64. doi: https://doi.org/10.18543/baidc-46-2012pp53-64

Marañón, B. y López, D. (2013). Una propuesta teóricometodológica crítica para el análisis de las experiencias populares colectivas de trabajo e ingresos. Hacia una alternativa societal basada en la reciprocidad. En B. Marañón (Ed.), La economía solidaria en México (pp. 25-58). Mexico D. F.: UNAM.

Pérez, A. et al. (2014). Manual de procedimientos administrativos para el balance cooperativo. México D. F.: Universidad Nacional Autónoma de México/Escuela Nacional de Trabajo Social.

Rodríguez, J. y Zeballos, M. (2007). Evaluación de proyectos de desarrollo local. Enfoques, métodos y procedimientos. Lima: Desco. 